\title{
5-(4-Pyridinyl)-1,3,4-oxadiazole-2-thiol on Gold: SAM Formation and Electroactivity
}

\author{
Tercio de F. Paulo, ${ }^{a}$ Maria A. S. da Silva, ${ }^{a}$ Solange de O. Pinheiro, ${ }^{a}$ Emerson Meyer, ${ }^{a}$ Lucidalva S. \\ Pinheiro, ${ }^{b}$ José A. Freire, ${ }^{\dagger, b}$ Auro A. Tanaka, ${ }^{c}$ Pedro de Lima Neto, ${ }^{d}$ Ícaro de S. Moreira ${ }^{a}$ and \\ Izaura C. N. Diógenes*a
}

${ }^{a}$ Departamento de Química Orgânica e Inorgânica, Centro de Ciências, Universidade Federal do Ceará, CP 12200, 60455-960 Fortaleza-CE, Brazil

${ }^{b}$ Departamento de Física, Centro de Ciências, Universidade Federal do Ceará, CP 6030, 60455-960 Fortaleza-CE, Brazil

\author{
${ }^{c}$ Departamento de Química, Centro de Ciências Exatas e Tecnologia. Universidade Federal do Maranhão, \\ Avenida dos Portugueses, s/n, 65085-580 São Luís-MA, Brazil \\ ${ }^{d}$ Departamento de Química Analítica e Físico Química, Centro de Ciências, Universidade Federal do Ceará, \\ CP 6035, Fortaleza-CE, Brazil
}

\begin{abstract}
O composto 5-(4-pyridinyl)-1,3,4-oxadiazole-2-thiol (Hpyt) adsorve espontaneamente sobre ouro formando SAMs ("Self-Assembled Monolayers") que, de acordo com os resultados eletroquímicos e de STM ("Scanning Tunneling Microscopy"), contêm poros através dos quais as moléculas dos complexos $\left[\mathrm{Fe}(\mathrm{CN})_{6}\right]^{4-}$ e $\left[\mathrm{Ru}\left(\mathrm{NH}_{3}\right)_{6}\right]^{3+}$ acessam a superfície livre de modificação. Para o complexo $\left[\mathrm{Fe}(\mathrm{CN})_{6}\right]^{4}$, a dependência da corrente faradáica com o $\mathrm{pH}$ da solução eletrolítica permitiu o cálculo do pKa da molécula de Hpyt adsorvida sobre ouro (4,2). Os parâmetros termodinâmicos, $\Delta \mathrm{H}_{\text {ads }}$ and $\Delta \mathrm{G}_{\text {ads }}$, para o processo de adsorção desta molécula foram estimados em $-20,01$ e $-39,39 \mathrm{~kJ} \mathrm{~mol}^{-1}$, respectivamente, utilizando-se o modelo de Langmuir. O processo redox da metaloproteína citocromo c foi estudado utilizando-se a SAM de Hpyt. A constante de velocidade heterogênea de transferência de elétrons foi calculada em $2,29 \times 10^{-3} \mathrm{~cm} \mathrm{~s}^{-1}$.
\end{abstract}

5-(4-pyridinyl)-1,3,4-oxadiazole-2-thiol (Hpyt) spontaneously adsorbs on gold forming SAMs (self-assembled monolayers) that, based on STM (Scanning Tunneling Microscopy) and electrochemical data, contain pinholes through which $\left[\mathrm{Fe}(\mathrm{CN})_{6}\right]^{4-}$ and $\left[\mathrm{Ru}\left(\mathrm{NH}_{3}\right)_{6}\right]^{3+}$ probe molecules access the underlying gold electrode. For the former molecule, the dependence of the faradaic current on the electrolyte solution $\mathrm{pH}$ value allowed the evaluation of the surface $\mathrm{pKa}$ as 4.2. The thermodynamic parameters $\Delta \mathrm{H}_{\text {ads }}$ and $\Delta \mathrm{G}_{\text {ads }}$ for the Hpyt adsorption process could be described by the Langmuir model and were calculated as -20.01 and $-39.39 \mathrm{~kJ} \mathrm{~mol}^{-1}$, respectively. Electrodic redox reaction of cytochrome c metalloprotein was accessed by using the Hpyt SAM with a heterogeneous electron transfer rate constant of $2.29 \times 10^{-3} \mathrm{~cm} \mathrm{~s}^{-1}$.

Keywords: oxadiazole, thiol, SAMs, STM, kinetic of adsorption, Cyt c

\section{Introduction}

Supramolecular assemblies constructed by using single electroactive molecules as building blocks, offer an interesting way to create electrically conducting materials whose organized architectures make them suitable for developing molecular electronic devices. In such a way, thiolate molecules have been used so far because both the

\footnotetext{
${ }^{\text {In memorian }}$

*e-mail: izaura@dqoi.ufc.br
}

strong affinity of sulfur to gold surfaces and formations of highly ordered self-assembled monolayers (SAMs). ${ }^{1-3}$ Progress toward this strategic goal demands not only the development of new synthetic approaches that yield highly ordered materials, but also careful attention to those elementary processes that dictate the heterogeneous electron transfer $\left(\mathrm{h}_{\mathrm{ET}}\right)$ through metal/monolayer interfaces. One aspect that affects this process is the thermodynamic stability of a monolayer. The magnitude of the adsorption free energy $\left(\Delta \mathrm{G}_{\mathrm{ads}}\right)$ gives a quantitative measure of 
adsorption strength, allowing insight into the chemical process of monolayer formation. For instance, results reported for the adsorption of $\mathrm{H}_{2} \mathrm{Q}\left(\mathrm{CH}_{2}\right)_{n} \mathrm{SH}$, where $\mathrm{H}_{2} \mathrm{Q}=$ hydroquinone, on gold $^{4}$ have shown a small dependence of $\Delta \mathrm{G}_{\text {ads }}$ with $n$, the alkyl spacer length, indicating that this parameter is mostly dominated by the gold-thiolate bond.

Pyridinic oxiadiazole compounds constitute an interesting class of modifier species since they have been systematically studied due to their luminescent properties and potential application in biological activities. ${ }^{5,6}$ Despite these aspects, there are no data in the literature concerning the use of this type of compound as electrochemical biological sensor. Within this compound class, 5-(4-pyridinyl)1,3,4-oxadiazole-2-thiol (Hpyt) species is particularly interesting because of the possibility to study the effect of SAM protonation equilibrium, which is one of the processes that influence $h_{E T}$. In fact, it is well known that the charge of SAMs may limit the electron transfer rate within biological systems where subtle changes in the chemical microenvironment surrounding the redox site can dramatically alter the ET rates. ${ }^{7}$

In this context, the objective of this work is to determine the thermodynamic parameters concerning the Hpyt adsorption process on gold. Also, by using Cyt c metalloprotein, $\left[\mathrm{Fe}(\mathrm{CN})_{6}\right]^{4-}$, and $\left[\mathrm{Ru}\left(\mathrm{NH}_{3}\right)_{6}\right]^{3+}$ complexes as probe molecules, to obtain a better understanding of the factors that influence $h_{E T}$.

\section{Experimental}

\section{Apparatus}

The electrochemical experiments were performed on a BAS 100W Electrochemical Analyzer (Bioanalytical Systems-BAS, West Lafayette, IN). A Nanoscope IIIA equipped with a standard Scanning Tunneling Microscopy (STM) head, able to read tunneling currents from $30 \mathrm{pA}$, was used to run the STM experiments. Tungsten wire 0.25 $\mathrm{mm}$ mechanically cut was used as tip. The high resolution STM images were obtained in the constant height mode. The electrochemical experiments with probe molecules were carried out by using a three-electrode configuration cell. For acquisition of the reductive desorption curves, a Teflon cell was used to prevent $\mathrm{KOH}$ chemical attack. Polycrystalline gold surfaces (BAS, A $=0.07 \mathrm{~cm}^{2}$ ) modified with Hpyt species and a gold flag were used as working and auxiliary electrodes, respectively. The polishing procedure of the gold surfaces was made as described by Qu et al. ${ }^{8}$ These electrodes were mechanically polished, rinsed and sonicated (10 min) in Milli-Q water. The electrode was then immersed in a freshly prepared "piranha solution" (3:1 concentrated $\mathrm{H}_{2} \mathrm{SO}_{4} / 30 \% \mathrm{H}_{2} \mathrm{O}_{2}$; CAUTION: Piranha solution is a high oxidant solution that reacts violently with organic compounds), rinsed exhaustively with water, and sonicated again. The cleanness was evaluated by comparison of the $i$ - $E$ curve obtained in a $0.5 \mathrm{~mol} \mathrm{~L}^{-1} \mathrm{H}_{2} \mathrm{SO}_{4}$ solution with the well-established curve for a clean gold surface. ${ }^{9}$ The electroactive area of this electrode was determined by means of cyclic voltammetry technique based on Randles-Sevick equation. ${ }^{10}$ For this purpose, a $0.5 \mathrm{~mol} \mathrm{~L}{ }^{-1} \mathrm{~K}_{2} \mathrm{SO}_{4}$ solution at $25{ }^{\circ} \mathrm{C}$ containing $0.1 \mathrm{mmol} \mathrm{L}^{-1}\left[\mathrm{Fe}(\mathrm{CN})_{6}\right]^{4}$ complex as redox active species and a diffusion coefficient value ${ }^{11}$ of $\mathrm{D}^{0}=6.32 \times 10^{-6} \mathrm{~cm}^{2} \mathrm{~s}^{-1}$ were used. Thus, the roughness factor of the gold electrode, given as the electrochemically determined area divided by the geometric area, was estimated as $c a$.1.4. The surface modification was made by immersing the gold electrode in an aqueous solution of the Hpyt ligand. For the STM measurements, flame annealed gold on mica samples were employed for molecular adsorption. For these experiments, the gold substrates were immersed for $30 \mathrm{~min}$ in a $2.0 \mathrm{mmol} \mathrm{L}^{-1}$ aqueous solution of Hpyt.

All potentials cited in the text are quoted in reference to the $\mathrm{Ag}|\mathrm{AgCl}| \mathrm{Cl}^{-}(\mathrm{BAS}, 3.5 \mathrm{M} \mathrm{KCl})$ electrode.

\section{Chemicals}

The water used throughout was purified in a Milli-Q water system (Millipore Co.). $\mathrm{K}_{4}\left[\mathrm{Fe}(\mathrm{CN})_{6}\right], \mathrm{KOH}$ and $\mathrm{KH}_{2} \mathrm{PO}_{4}$ compounds, from Aldrich, were used without further purification. $\left[\mathrm{Ru}\left(\mathrm{NH}_{3}\right)_{6}\right] \mathrm{Cl}_{3}$, from Johnson Matthey, and high-purity $\mathrm{H}_{2} \mathrm{SO}_{4}$, from Merck, were used as received. Horse heart cytochrome c (type VI, 99\%, Aldrich Co.) was purified as described elsewhere. ${ }^{12}$ 5-(4-Pyridinyl)1,3,4-oxadiazole-2-thiol ligand was synthesized according to the literature procedure. ${ }^{13} \mathrm{~A} 0.1 \mathrm{~mol} \mathrm{~L}^{-1}$ phosphate buffer solution $(\mathrm{pH}=7.0)$ was used for the metalloprotein electrochemical experiments. For the inorganic probe molecules, $0.1 \mathrm{~mol} \mathrm{~L}^{-1} \mathrm{KCl}$ solutions were used as electrolyte medium. For the electrochemical measurements in $\mathrm{KCl}$ solutions of different $\mathrm{pH}$ values, the $\mathrm{pH}$ was adjusted with either $\mathrm{HCl}$ or $\mathrm{NaOH}$ and monitored by a $\mathrm{pH}$ meter.

\section{Results and Discussion}

\section{SAM characterization}

\section{Reductive desorption results}

Linear sweep voltammetry (LSV) technique was used to evaluate the AuS bond strength. According to literature, ${ }^{14-16}$ the reductive potential sweep in alkaline electrolyte $\left(0.5 \mathrm{~mol} \mathrm{~L}^{-1} \mathrm{KOH}\right)$ of gold surfaces modified 
with alkanethiolates presents one wave assigned to the $\mathrm{AuSR}+\mathrm{e}^{-} \rightarrow \mathrm{Au}+\mathrm{SR}^{-}$reaction with the reductive desorption potential $\left(\mathrm{E}_{\mathrm{rd}}\right)$ directly related to the bond strength. At room temperature, the reductive desorption process of the Hpyt SAM from gold was observed at $-0.55 \mathrm{~V}$ with a reductive desorption charge density $\left(\sigma_{\mathrm{rd}}\right)$ of $20.10 \mu \mathrm{C}$ $\mathrm{cm}^{-2}$. This value is smaller than those observed for the desorption of monolayers formed with $n$-alkanethiolates, ${ }^{17}$ ca. $75 \mu \mathrm{Ccm}^{-2}$, or 4-mercaptopyridine (pyS), ${ }^{16} \mathrm{ca} .50 \mu \mathrm{Ccm}^{-2}$, on gold. The smaller $\sigma_{\mathrm{dr}}$ value for the Hpyt SAM can be associated with the packing limitation imposed by the larger electronic density of two aromatic rings in comparison to a fully extended alkyl chain of alkanethiolates and to one pyridine ring of pyS. The $\mathrm{E}_{\mathrm{rd}}$ value $(-0.55 \mathrm{~V})$ is almost equal to that reported for the SAM formed with pyS on gold, $\mathrm{E}_{\mathrm{rd}}=-0.56 \mathrm{~V} \cdot{ }^{16,18}$ For the pyS SAM, surface-enhanced Raman scattering (SERS) data indicated a sigma $(\sigma)$ interaction with the gold surface atoms. ${ }^{19}$ With this consideration in mind, the Hpyt adsorption on gold must involve the same type of interaction, i.e. a sulfur $\sigma$ bond. In fact, the SAM formed with 1,4-dithiane molecules, for which an additional $\pi$ interaction is suggested based on SERS results, is electrochemically desorbed at $-0.87 \mathrm{~V} v s$. $\mathrm{Ag}|\mathrm{AgCl}| \mathrm{Cl}^{-}$in alkaline medium. ${ }^{20}$

Hpyt surface coverages $\left(\Gamma_{\mathrm{i}}\right)$ were calculated from the area under the LSV wave by using the $\Gamma_{\mathrm{i}}=\sigma_{\mathrm{dr}} /(\mathrm{nF})$ equation, where $n$ is the electron number involved in the electrode reaction and $\mathrm{F}$ is the Faraday constant. The $\Gamma$ values for the Hpyt SAM were found to be strongly dependent on the Hpyt concentration in solution, thus allowing the process to be described by the diffusioncontrolled Langmuir adsorption. ${ }^{10}$ Figure 1 presents the dependence of $\Gamma_{\mathrm{i}}$ on the immersion time, and on the Hpyt bulk concentration, [Hpyt]. The Langmuir relation, $\Gamma_{i} /[\mathrm{Hpyt}]$ vs. [Hpyt], is also presented. The dependence of $\Gamma_{i}$ with the immersion time (Figure 1a) indicates that the Hpyt adsorption process occurs in two steps, as also reported in the literature for some thiolate monolayers. ${ }^{3} \mathrm{~A}$ very fast step (only few minutes), assigned to the surfacehead group $(\mathrm{Au}-\mathrm{S})$ reaction, and a second one, described as a surface crystallization process where a long-term structural reorganization takes place.

For the Langmuir model to be suitable for the data treatment of a given adsorption system, a plot of $\mathrm{C}_{\mathrm{i}} / \Gamma_{\mathrm{i}}$ versus $C_{i}$ should be linear, according to: ${ }^{10}$

$$
\frac{\mathrm{C}_{\mathrm{i}}}{\Gamma_{\mathrm{i}}}=\frac{1}{\beta_{\mathrm{i}} \Gamma_{\mathrm{S}}}+\frac{\mathrm{C}_{\mathrm{i}}}{\Gamma_{\mathrm{S}}}
$$

where $\mathrm{C}_{\mathrm{i}}=[\mathrm{Hpyt}]$, the bulk concentration of the Hpyt molecules in solution, $\Gamma_{\mathrm{i}}$ and $\Gamma_{\mathrm{S}}$ are the Hpyt surface
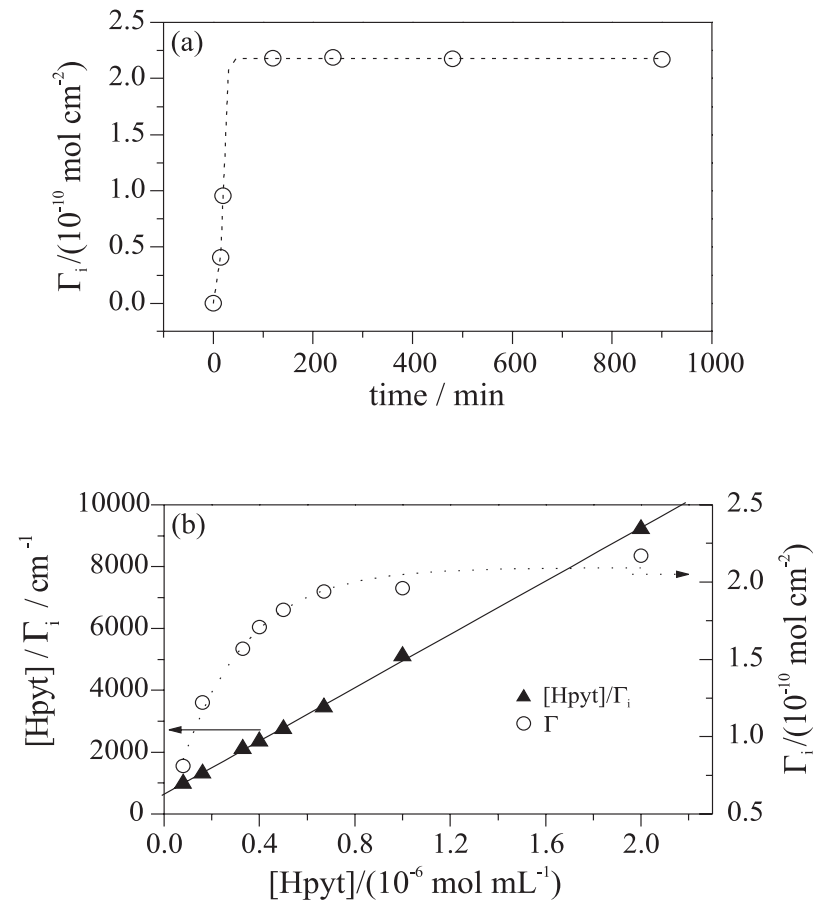

Figure 1. Plots of (a) $\Gamma_{\mathrm{i}} v s$. immersion time of the gold electrode in a $2.0 \times 10^{-3} \mathrm{~mol} \mathrm{~L}^{-1}$ Hpyt solution, and (b) $[\mathrm{Hpyt}] / \Gamma_{\mathrm{i}} v s$. [Hpyt] and $\Gamma_{\mathrm{i}} v s$. [Hpyt]. Data obtained at $30^{\circ} \mathrm{C}$.

coverages at equilibrium and saturation, respectively, and $\beta_{\mathrm{i}}$ is the adsorption coefficient. As it can be seen from Figure $1 \mathrm{~b}$, the plot of $[\mathrm{Hpyt}] / \Gamma_{\mathrm{i}}$ versus $[\mathrm{Hpyt}]$ is linear, indicating that the diffusion-controlled Langmuir model well describes the initial step of the Hpyt adsorption process on gold. This linearity was observed for all plots obtained in the temperature range from 10 to $50{ }^{\circ} \mathrm{C}$. Table 1 presents the data of the Hpyt surface and bulk concentrations at different temperatures, illustrating the strong dependence of the adsorption initial step with the Hpyt concentration.

Table 1. Values of $\Gamma_{\mathrm{i}}, \Gamma_{\mathrm{S}}$, and $\ln \beta$ for the the Hpyt adsorption process on gold at different temperatures and concentrations

\begin{tabular}{lccccc}
\hline $\begin{array}{l}\mathrm{Hpyt}] \times 10^{6} / \\
\mathrm{mol} \mathrm{mL}^{-1}\end{array}$ & $10^{\circ} \mathrm{C}$ & $25^{\circ} \mathrm{C}$ & $30^{\circ} \mathrm{C}$ & $40{ }^{\circ} \mathrm{C}$ & $50^{\circ} \mathrm{C}$ \\
\hline 2.00 & 1.71 & 1.99 & 2.17 & 2.46 & 1.85 \\
1.00 & 1.71 & 1.92 & 1.96 & 2.04 & 1.39 \\
0.67 & 1.35 & 1.78 & 1.94 & 1.61 & 1.26 \\
0.50 & 1.19 & 1.49 & 1.82 & 1.49 & 1.07 \\
0.40 & 1.57 & 1.62 & 1.71 & 1.78 & 1.04 \\
0.33 & 1.49 & 1.63 & 1.57 & 1.54 & 0.92 \\
0.16 & 0.91 & 1.23 & 1.22 & 1.26 & 0.58 \\
0.08 & 0.69 & 0.94 & 0.81 & 0.93 & 0.51 \\
$\ln \beta_{\mathrm{i}}$ & 15.75 & 15.85 & 15.77 & 15.46 & 15.39 \\
$\Gamma_{\mathrm{S}} \times 10^{10} / \mathrm{mol} \mathrm{cm}^{-2}$ & 1.85 & 2.12 & 2.27 & 2.58 & 1.64 \\
\hline
\end{tabular}


The values of $\Gamma_{\mathrm{S}}$ and $\beta_{\mathrm{i}}$ were obtained from the slope $\left(1 / \Gamma_{\mathrm{S}}\right)$ and intercept $\left(1 / \Gamma_{\mathrm{s}} \beta_{\mathrm{i}}\right)$, respectively, of $[\mathrm{Hpyt}] / \Gamma$ versus [Hpyt] plots at different temperatures, and are displayed in Table 1 . From the $\beta_{\mathrm{i}}$ values obtained at different temperatures and based on the equation $\Delta \mathrm{G}_{\mathrm{ads}}=-\mathrm{RT} \ln \beta_{\mathrm{i}},{ }^{10}$ the free energy of adsorption $\left(\Delta \mathrm{G}_{\mathrm{ads}}\right)$ for the Hpyt adsorption process was calculated as $c a$. $-39.39 \mathrm{~kJ} \mathrm{~mol}^{-1}$. This value is in good agreement with those reported for the adsorption process of molecules that contain aromatic fragments, such as $\mathrm{H}_{2} \mathrm{Q}\left(\mathrm{CH}_{2}\right)_{\mathrm{n}} \mathrm{SH}$ (ca. $-37.45 \mathrm{~kJ} \mathrm{~mol}^{-1}$ ) and azobenzenecarboxamydoethylthiol $\left(-37.03 \mathrm{~kJ} \mathrm{~mol}^{-1}\right)$ on gold. ${ }^{21,22}$ On the other hand, it is almost two times greater than those reported for the adsorption of some alkanethiolates on gold. ${ }^{23}$ This observation reflects the dependence of the surface-head group reaction on the electron density of the adsorbing sulfur. In fact, monolayers formed with inorganic complexes that enhance the electron density on the sulfur adsorbing atom, as consequence of a $\pi$-back-bonding interaction, have shown to be more robust than their organic counterparts. ${ }^{17,24,25}$ Also, the negative free energy value indicates the feasibility of the process and its spontaneous nature.

The change in enthalpy $\left(\Delta \mathrm{H}_{\mathrm{ads}}\right)$ of the Hpyt adsorption process was calculated by using the following equation:

$\Delta H_{a d s}=-R\left(\frac{T_{1} \times T_{2}}{T_{1}-T_{2}}\right) \ln \frac{\beta_{2}}{\beta_{1}}$

where $T$ is the temperature in Kelvin, and $\beta_{1}$ and $\beta_{2}$ are the adsorption coefficients (obtained from the Langmuir isotherm) at $\mathrm{T}_{1}$ and $\mathrm{T}_{2}$ temperatures, respectively, and resulted to be approximately $-20.1 \mathrm{~kJ} \mathrm{~mol}^{-1}$. The negative value of $\Delta \mathrm{H}_{\text {ads }}$ indicated the exothermic nature of the Hpyt adsorption process.

\section{STM measurements}

Tunneling currents in the range of 50-100 pA and 200-600 mV bias voltage were employed to avoid tip interactions with the adsorbed layer. These experimental parameters were chosen since the Hpyt molecule is quite long and strong interaction with the tip during scanning could take place in a way similar to that observed for long chain alkyl thiols. ${ }^{26}$ Low resolution images of the gold sample after self-assembly show a few defects on the terraces. The images of the structure were very transitory because scanning disrupted the molecular layer and higher tunneling resistances could not be reached with the set-up employed.

Figure 2 shows a typical STM image of the Hpyt lattice on $\mathrm{Au}$ (111). Pinholes on the molecular structure are

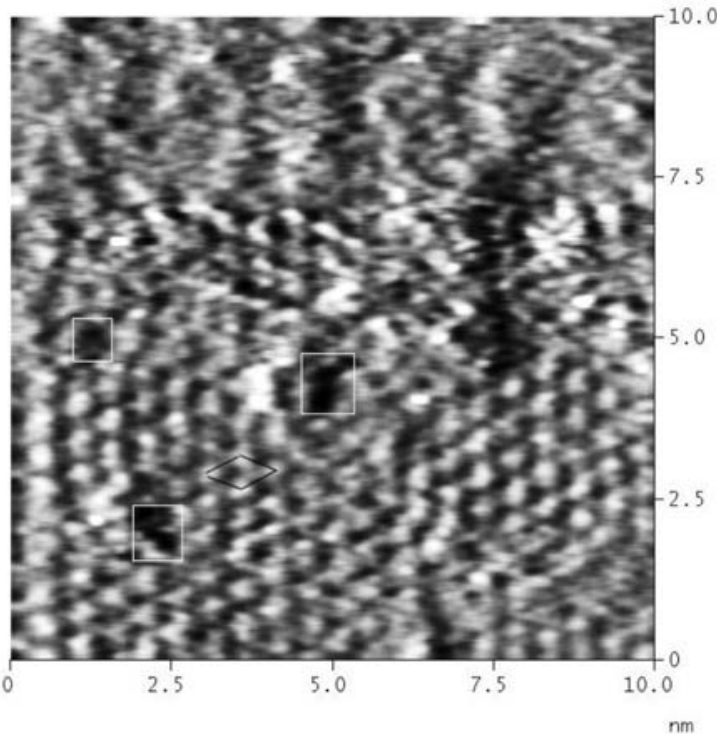

Figure 2. STM image of the Hpyt layer on Au (111). Surface area: $100 \times 100 \AA^{2}$. Bias voltage: $200 \mathrm{mV}$. Tunneling current: $100 \mathrm{pA}$. White rectangles show pinholes in the layer. Black rectangle delimits unit cell.

observed and the tip loses resolution in the upper part of the frame. The molecular lattice observed at high resolution is hexagonal with lattices parameters of $5.5 \pm 0.4 \times 5.5 \pm 0.4 \AA$. Such values show that a slight mismatch with the wellknown $\sqrt{3} \mathrm{x} \sqrt{ } 3 \mathrm{R} 30^{\circ}$ structure is present in the Hpyt layer. This behavior has been found for other aromatic thiols on $\mathrm{Au}(111),{ }^{27}$ and the influence of the aromatic group discussed as an important factor in the lattice ordering. ${ }^{27-30}$ The imperfection of the Hpyt lattice seems to derive from the rigidity of the groups attached to the sulfur head. The two aromatic rings in the Hpyt structure could have lateral interactions in the adsorbed layer. The most effective interaction would be in the form of $\pi$-stacking. The molecules, however, may have their $\pi$ electron density in parallel or in a twisted configuration.

The pyridine ring can rotate freely and may assume a position where the $\pi$ electron density is parallel to the gold surface or adopts a side-on conformation. The diversity of conformations could lead to weak lateral forces acting between the aromatic groups. This property reflects in the formation of the lattice leading to pinholes in the molecular structure since strong lateral interaction does not happen effectively. This results in small domains, which are seen in the STM images. For a polycrystalline electrode, a smaller coverage could be found since several defects on the surface would not permit the formation of an extended molecular lattice. This result reinforces those obtained from the reductive desorption measurements which suggest that the Hpyt SAM is less packed and ordered than SAMs formed with alkanethiolates on gold. ${ }^{17}$ 
Even comparing the Hpyt $\Gamma$ values to those obtained for the very similar pyS molecule, ${ }^{16}$ the Hpyt SAM is still less packed. This observation may be assigned to weak lateral forces between the Hpyt adjacent molecules as suggested by the STM results.

\section{Electroactivity of the Hpyt SAM}

The electroactivity of the Hpyt SAM on gold was evaluated by using Cyt c metalloprotein, and $\left[\mathrm{Fe}(\mathrm{CN})_{6}\right]^{4-}$ and $\left[\mathrm{Ru}\left(\mathrm{NH}_{3}\right)_{6}\right]^{3+}$ inorganic complexes as probe molecules.

\section{Cyt c electrochemical studies}

Figure 3 presents the cyclic voltammograms obtained at different scan rates for the Hpyt SAM in Cyt c solution. Plots of cathodic peak current $\left(\mathrm{i}_{\mathrm{pc}}\right)$ versus square root of scan rate $\left(\mathrm{v}^{1 / 2}\right)$ and Nicholson's kinetic parameter $(\Psi) v s$. reciprocal of scan rate $\left(\mathrm{v}^{-1}\right)$ are also presented in this Figure.

For the bare gold electrode (dotted line in Figure 3a), no faradaic response typically assigned to $\mathrm{Fe}^{\mathrm{III/II}}$ redox process of the Cyt $\mathrm{c}$ is observed within the potential range used. On the contrary, the curves obtained with the Hpyt SAM as working electrode (solid lines in Figure 3a) presented waves with peak potentials dependent on the scan rate, indicating a quasi-reversible process. ${ }^{10}$ According to the literature, the half-wave potential observed at $0.05 \mathrm{~V}$ for

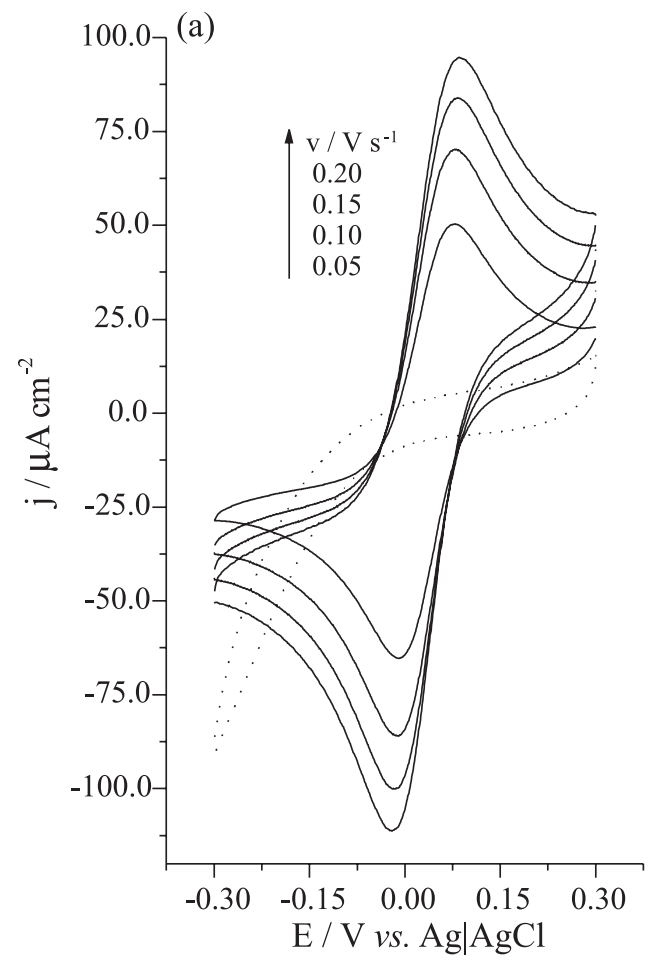

$0.05 \mathrm{~V} \mathrm{~s}^{-1}$ is consistent with the native form of the protein. ${ }^{31}$ Also, the observation of such potential suggests that there is no change in the protein conformation in consequence of the SAM-Cyt c molecular recognition process. ${ }^{32,33}$ Based on the Nicholson's method, ${ }^{34}$ the dependence of the difference between the anodic and cathodic peak potentials $\left(\Delta \mathrm{E}_{\mathrm{p}}\right)$ on the scan rate allows one to estimate the kinetic parameter, $\Psi$. Based on equation 3 with $\mathrm{f}=\mathrm{F} / \mathrm{RT}$, the heterogeneous electron transfer rate constant, $k^{0}$, was determined from the slope of the curve presented in the plot of $\Psi^{2} v s$. the reciprocal of the scan rate, $\mathrm{v}^{-1}$ (Figure $3 \mathrm{c}$ ).

$$
\Psi^{2}=\frac{1}{v} \frac{\left(k^{0}\right)^{2}}{\left[D^{0} \pi(n f)\right]}
$$

For the calculation of the $\Psi$ parameter, a diffusion coefficient of $1.0 \times 10^{-6} \mathrm{~cm}^{2} \mathrm{~s}^{-1}$ was used. ${ }^{35}$ The $k^{0}$ value calculated for the Cyt c on Hpyt SAM was $2.29 \times 10^{-3} \mathrm{~cm} \mathrm{~s}^{-1}$ and resulted to be lower than those calculated for the SAMs formed with pyS $\left(6.0 \times 10^{-3} \mathrm{~cm} \mathrm{~s}^{-1}\right)$ and $\left[\mathrm{Ru}(\mathrm{CN})_{5}(\mathrm{pyS})\right]^{3-}$ complex $\left(8.0 \times 10^{-3} \mathrm{~cm} \mathrm{~s}^{-1}\right)$ on gold. ${ }^{24,36}$ Taking into account the similarity between the charge density on the terminal group of these modifiers and on the nitrogen terminal atom of the Hpyt SAM, the results can be explained by differences in the configuration of the adsorbates on surface. Previously reported results ${ }^{19,24}$ indicate a trans conformation of pyS and $\left[\mathrm{Ru}(\mathrm{CN})_{5}(\mathrm{pyS})\right]^{3-}$ adsorbates on gold surface. The terminal
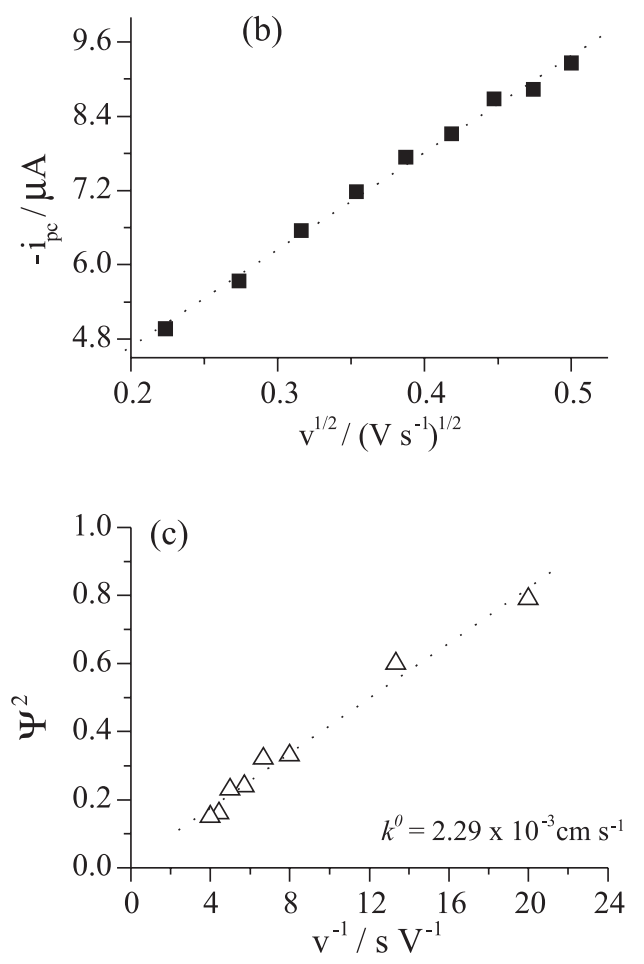

Figure 3. (a) Cyclic voltammograms in a $0.1 \mathrm{~mol} \mathrm{~L}^{-1} \mathrm{KH}_{2} \mathrm{PO}_{4}$ solution $(\mathrm{pH}=7.0)$ containing $0.1 \mathrm{mmol} \mathrm{L}^{-1} \mathrm{Cyt}_{\mathrm{c}}$ for the $\mathrm{Hpyt} \mathrm{SAM}$ on gold (solid line) at different scan rates, and on bare gold electrode (dotted line) at $0.05 \mathrm{~V} \mathrm{~s}^{-1}$; and plots of (b) $-\mathrm{i}_{\mathrm{pc}} v s . \mathrm{v}^{1 / 2}$, and (c) $\Psi^{2} v s$. $\mathrm{v}^{-1}$ (data extracted from Figure $3 \mathrm{a}$ ). 
functional group in these modifiers is directly pointing to the Cyt c molecules in the electrolytic phase. For the Hpyt molecules, however, the STM data in conjunction with $\Gamma$ values indicate a disordered monolayer with the nitrogen terminal atom not directly pointing to the Cyt $\mathrm{c}$ molecules in solution. This non-trans arrangement of the Hpyt molecules on the surface may lead to difficulties in the heterogeneous molecular recognition, thus reducing the rate of the Cyt c electron transfer process.

\section{Inorganic complexes as probe molecules}

Figure 4 shows the voltammograms obtained in $\mathrm{KCl}$ solution containing $\left[\mathrm{Fe}(\mathrm{CN})_{6}\right]^{4-}$ and $\left[\mathrm{Ru}\left(\mathrm{NH}_{3}\right)_{6}\right]^{3+}$ complexes. On the bare gold electrode, the half-wave formal potentials $\left(\mathrm{E}_{1 / 2}\right)$ assigned to $\mathrm{Fe}^{\mathrm{III/II}}$ and $\mathrm{Ru}^{\mathrm{III/II}}$ redox processes were observed, respectevely, at 0.22 and $-0.18 \mathrm{~V}$, as previously reported. . $^{37,38}$

According to the literature ${ }^{39-41}$ the framework portion of a monolayer is sufficiently thick that it can block electron transfer between the underlying electrode surface and solution phase redox probe molecules. However, probe molecules that have the right combination of physical and chemical characteristics can penetrate the framework in the vicinity of template-induced defect sites and exchange electrons with the underlying Au electrode surface. Based on the theory developed by Amatore et al. ${ }^{39}$ the shape of the resulting cyclic voltammogram can be related to the size and number density of defects (or pores) within the

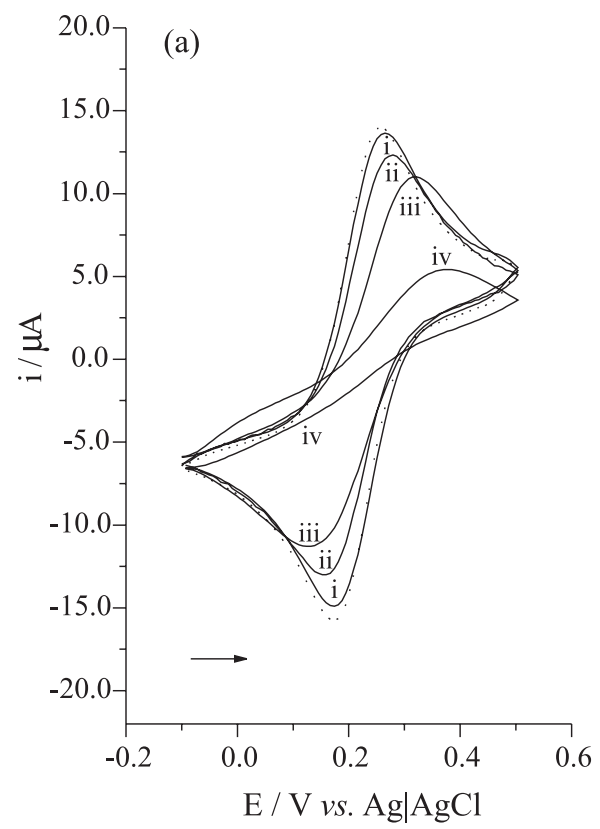

film. Therefore, if there is an interpore distance at which the diffusion layers of individual pores do not overlap, for instance, a voltammogram characteristic of radial diffusion is obtained. On the other hand, when the monolayer is not so dense that the redox species in solution can easily assess the underlying metallic surface, a voltammetric curve characteristic of linear diffusion is obtained.

In fact, the $\mathrm{h}_{\mathrm{ET}}$ reaction of the $\left[\mathrm{Fe}(\mathrm{CN})_{6}\right]^{3-}$ complex is strongly affected by the immersion time of the gold surface in Hpyt solution, as it can be observed from the voltammograms presented in Figure 4a, which change from a linear diffusion (curve $i$ ) to an almost radial diffusion shape (curve $i v$ ). As the immersion time is increased, an increase in the $\Delta \mathrm{E}_{\mathrm{p}}$ parameter is observed and, at the same time, the current is reduced, indicating a slower $\mathrm{h}_{\mathrm{ET}}$ kinetic. These results suggest that the ET reaction is occurring at pinhole sites. The increase in the surface coverage reduces the pore density within the Hpyt monolayer making it harder for the $\left[\mathrm{Fe}(\mathrm{CN})_{6}\right]^{4-}$ molecules to reach the underlying gold surface. Therefore, it can be concluded that the Hpyt monolayer contains small defects spaced sufficiently far apart to allow the diffusion of the probe molecules to the surface. This conclusion implies a SAM not so ordered for the Hpyt species compared with those formed by $n$-alkanethiolates ${ }^{3,15-17,40}$ on gold. This observation reinforces the results obtained from the reductive desorption and STM measurements which indicate a surface coverage lower than the values reported for alkanethiolates on gold and small domains on surface, respectively. As already

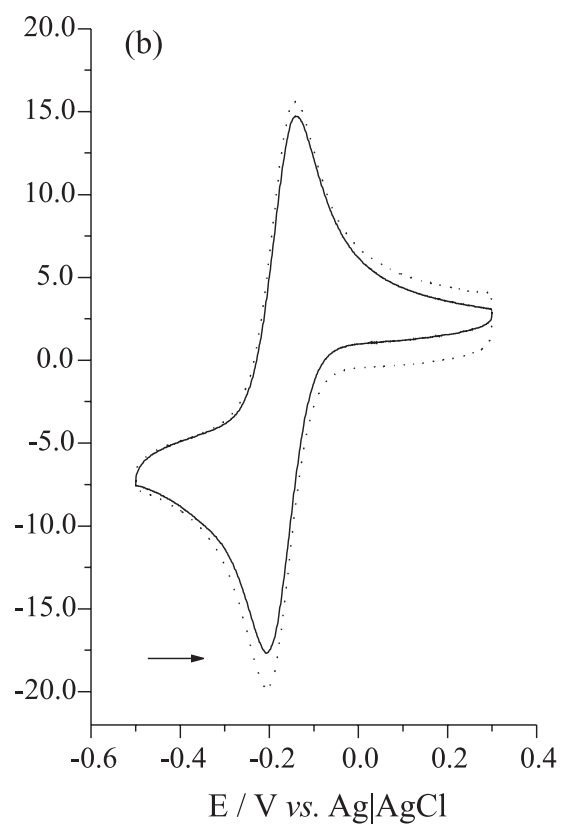

Figure 4. Cyclic voltammograms recorded at $0.10 \mathrm{~V} \mathrm{~s}^{-1}$ in a $0.1 \mathrm{~mol} \mathrm{~L}^{-1} \mathrm{KCl}$ solution $(\mathrm{pH}=6.0)$ containing (a) $1.0 \mathrm{mmol} \mathrm{L}^{-1}[\mathrm{Fe}(\mathrm{CN})]_{6}^{4-}$ on gold electrode after $5(i), 30$ (ii), 60 (iii), and $900 \mathrm{~min}$ (iv) of immersionin Hpytsolution; and(b) $1.0 \mathrm{mmolL}^{-1}\left[\mathrm{Ru}\left(\mathrm{NH}_{3}\right)_{6}\right]^{3+}$ for the goldelectrode after 900 min of immersionin Hpytsolution (solid line). $[\mathrm{Hpyt}]=2.0 \mathrm{mmol} \mathrm{L}^{-1}$. Dotted lines are used for bare gold substrates. 
commented, the observation of a SAM not so packed for the Hpyt molecules must be due to a steric limitation imposed by the aromatic groups.

For the $\left[\mathrm{Ru}\left(\mathrm{NH}_{3}\right)_{6}\right]^{3+}$ probe molecule, no significant change is observed in the cyclic voltammogram obtained for the gold electrode after immersion in the Hpyt solution in relation to that obtained for the bare gold substrate (Figure 4b).

Actually, the ET reaction should be facile since the $k^{0}$ values of the probe molecules are very high, $k^{0}=0.15 \mathrm{~cm} \mathrm{~s}^{-1}$ and $k^{0}>1 \mathrm{~cm} \mathrm{~s}^{-1}$ for $\left[\mathrm{Fe}(\mathrm{CN})_{6}\right]^{4-}$ and $\left[\mathrm{Ru}\left(\mathrm{NH}_{3}\right)_{6}\right]^{3+}$, respectively. ${ }^{37,38} \mathrm{Also}$, the hydrated diameter is almost equal for both probe molecules, $c a$. $6.2 \AA{ }^{40,41}$ suggesting that the size of the pinholes is not affecting the heterogeneous molecular recognition process, which is distinctly experienced by the probe molecules. Similar behavior was observed by Chailapakul et al. ${ }^{40}$ for a mixed monolayer of 4-hydroxythiophenol and 1-hexadecanethiol on gold and using $\left[\mathrm{Fe}(\mathrm{CN})_{6}\right]^{4-}$ and $\left[\mathrm{Ru}\left(\mathrm{NH}_{3}\right)_{6}\right]^{3+}$ as probe molecules. Although without an unambiguous evidence to identify the interaction between the probe molecules and the adsorbates, the authors ${ }^{40}$ suggested that the sign of the charge on the complexes may affect the molecular discrimination. The results presented in this work reinforce this suggestion.

The $h_{\mathrm{ET}}$ reaction of the $\left[\mathrm{Fe}(\mathrm{CN})_{6}\right]^{4-}$ probe molecule is shown to be strongly dependent on the $\mathrm{pH}$ value of the bulk electrolyte solution, as illustrated in Figure 5. For the bare gold electrode, no changes in the voltammogram shape were observed in the $\mathrm{pH}$ range from 2.0 to 12.0.

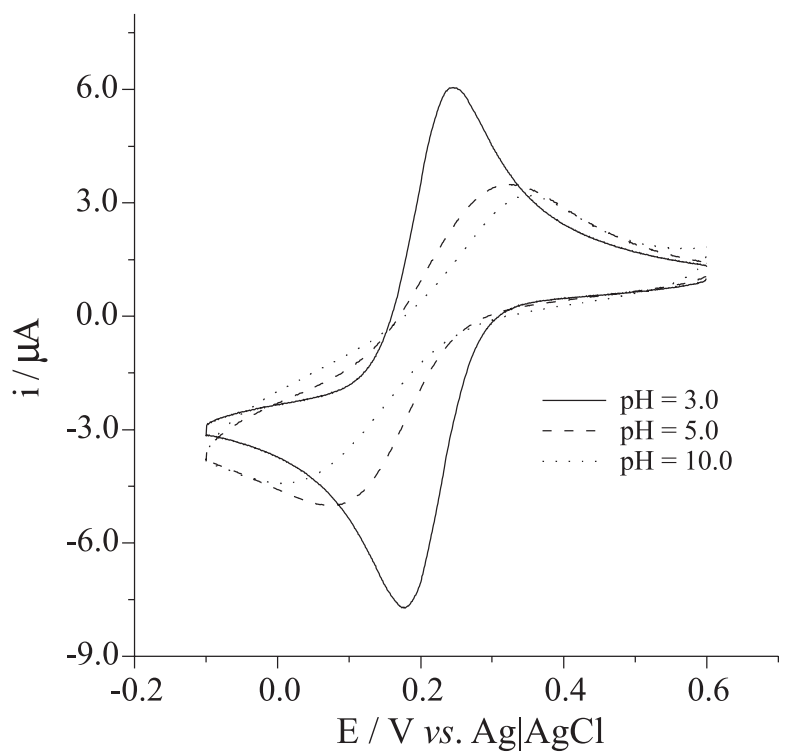

Figure 5. Cyclic voltammograms recorded at $0.15 \mathrm{Vs}^{-1}$ in a $0.1 \mathrm{~mol} \mathrm{~L}^{-1} \mathrm{KCl}$ solution containing $1.0 \mathrm{mmol} \mathrm{L}^{-1}\left[\mathrm{Fe}(\mathrm{CN})_{6}\right]^{4-}$ at different $\mathrm{pH}$ values. Data obtained after 90 min of immersion of the gold electrode in Hpyt solution.
Depending on the $\mathrm{pH}$ value of the electrolyte solution, the protonation equilibrium alters the ionization state of pyridyl containing SAMs. ${ }^{42-44}$

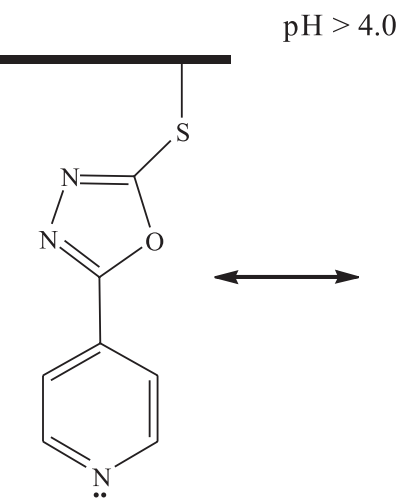

(I)

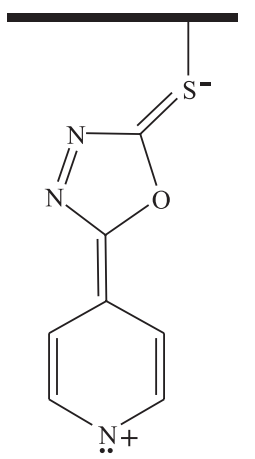

(II)

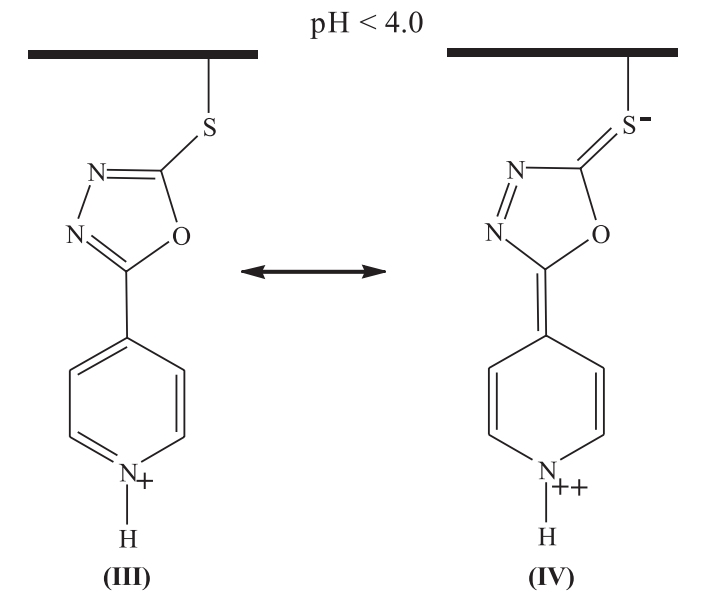

Scheme 1. Ionization behavior and resonance structures of the Hpyt SAMs on gold.

Considering the results presented in Figure 5 and those reported in the literature, ${ }^{42-44}$ a model based on the resonance structures of the Hpyt molecules on gold is suggested in Scheme 1 to explain the changes in the voltammograms of the $\left[\mathrm{Fe}(\mathrm{CN})_{6}\right]^{4-}$ probe molecule. At $\mathrm{pH}>4.0$, two resonance forms, I and II, can be proposed, with the real structure between them. At $\mathrm{pH}<4.0$, although two structures may be suggested for the final resonance hybrid, III and IV, the latter contains two positive charges on the pyridyl nitrogen atom thus not making a major contribution. From the model proposed in Scheme 1, it can be concluded that above $\mathrm{pH} 4.0$, the negative charge density on the Hpyt end group hardly affects or even inhibits the $h_{E T}$ reaction of the probe, as can be seen from the voltammograms presented in Figure 5. Therefore, the voltammetric profiles presented in Figure $4(\mathrm{pH}=6.0)$ can be explained by considering that longer immersion times decrease the density of pinholes increasing the negative 
charge density on surface. The electrostatic repulsion between the negative charge density on the modifier and the $\left[\mathrm{Fe}(\mathrm{CN})_{6}\right]^{4-}$ probe species must affect the heterogeneous molecular recognition process reducing the $h_{E T}$ rate. On the other hand, for the $\left[\mathrm{Ru}\left(\mathrm{NH}_{3}\right)_{6}\right]^{3+}$ probe molecule, the opposite charges seems to favor or, at least, not affect the heterogeneous molecular recognition process. Also, for this compound, the electrostatic interaction may be inducing a closer approach to the electrode surface. Thus, the total current assigned to the $\mathrm{Ru}^{\mathrm{IIIIII}}$ process may be resultant from the contribution of tunneling current through the Hpyt SAM and the direct electron transfer at the pinholes.

Once the faradaic current of the $\left[\mathrm{Fe}(\mathrm{CN})_{6}\right]^{4-}$ probe molecule has been shown to be dependent on the $\mathrm{pH}$ value when the Hpyt SAM is used, the surface pKa of this modifier can be calculated from the voltammograms obtained at different $\mathrm{pH}$ values. The faradaic current can be described as,

$$
\mathrm{i}=\mathrm{i}_{\mathrm{Hpyt}-}\left[\mathrm{Hpyt}^{-}\right]+\mathrm{i}_{\mathrm{HpytH}}[\mathrm{HpytH}]
$$

where $\mathrm{Hpyt}^{-}$and $\mathrm{HpytH}$ are the dissociated and nondissociated forms of the Hpyt SAM, and $i_{\text {Hpyt- }}$ and $i_{\text {HpytH }}$ are the faradaic currents from the redox reaction of the $\left[\mathrm{Fe}(\mathrm{CN})_{6}\right]^{4-}$ probe molecule on $\mathrm{Hpyt}^{-}$and HpytH structures, respectively. The $\mathrm{i}_{\text {Hpyt- }}$ and $\mathrm{i}_{\text {HpytH }}$ currents can be determined from the average values at $\mathrm{pH}$ values above and below 6.0 and 3.5, respectively. Then, by using $\left[\mathrm{Hpyt}^{-}\right]^{+}[\mathrm{HpytH}]=1$ and correlating the equation 4 with the well-known $\mathrm{pK}_{\mathrm{a}}$ equation, the surface $\mathrm{pK}_{\mathrm{a}}$ can be calculated from:

$$
\left.\mathrm{pK}_{\mathrm{a}}=\mathrm{pH}-\log \left\{\left[\left(\mathrm{i}_{\text {HpytH }}-\mathrm{i}_{\text {Hpyt }}\right) /\left(\mathrm{i}-\mathrm{i}_{\text {Hpyt- }}\right)\right]-1\right]\right\}
$$

The curve obtained from the application of the experimental results in this equation is presented in Figure 6 , from which the surface $\mathrm{pK}_{\mathrm{a}}$ was calculated as 4.2 . The curve is very similar to that reported for the electrochemical titration of the pyS SAM on gold ${ }^{44}$ and it indicates that the $\mathrm{h}_{\mathrm{ET}}$ reaction of the $\left[\mathrm{Fe}(\mathrm{CN})_{6}\right]^{4-}$ probe is strongly sensible to the protonation equilibrium on the nitrogen atom of the pyridine ring.

\section{Conclusions}

STM and reductive desorption results showed that the packing limitation of the Hpyt molecules on gold surface is due to the electronic density of the aromatic fragments. As consequence of this packing limitation, weak interaction, if any, is observed between the adjacent Hpyt adsorbed molecules thus allowing the adsorption process to be described by the Langmuir model. From the relation

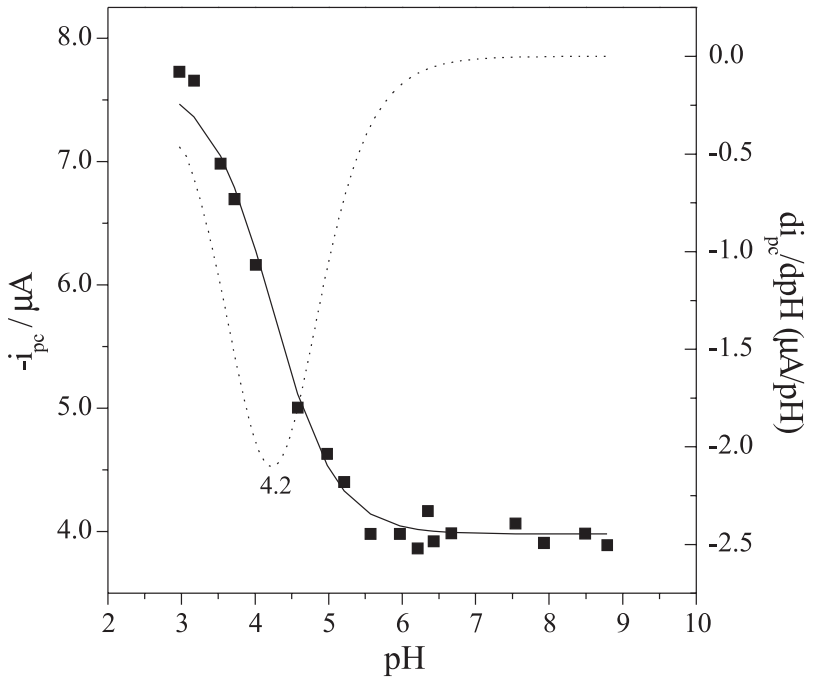

Figure 6. Dependence of the cathodic peak current with the solution $\mathrm{pH}$ (solid line) and differential curve of the experimental results (dotted line).

between the adsorbed and bulk solution concentrations of the Hpyt molecules at different temperatures, the free energy of adsorption was calculated as $c a .-39.39 \mathrm{~kJ} \mathrm{~mol}^{-1}$. The negative value of the change in the adsorption enthalpy, $\Delta$ Hads, indicated the exothermic nature of the Hpyt adsorption process. The gold electrode modified with the Hpyt molecules shown to successfully assess the heterogeneous electron transfer process of the cytochrome c metalloprotein as well as that of the $[\mathrm{Fe}(\mathrm{CN}) 6]^{4-}$ and $[\mathrm{Ru}(\mathrm{NH} 3) 6]^{3+}$ complexes. For the former molecule, the dependence of the faradaic current on the electrolyte solution $\mathrm{pH}$ value allowed the evaluation of the surface pKa as 4.2.

\section{References}

1. Love, J. C.; Estroff, L. A.; Kriebel, J. K.; Nuzzo, R. G.; Whitesides, G. M.; Chem. Rev. 2005, 105, 1103.

2. Witt, D.; Klajn, R.; Barski, P.; Grzybowski, B. A.; Curr. Org. Chem. 2004, 8, 1763.

3. Ulman, A.; Chem. Rev. 1996, 96, 1533.

4. Hong, H.-G.; Park, W.; Electrochim. Acta 2005, 51, 579.

5. Nofal, Z. M.; Fahmy, H. H.; Mohamed, H. S.; Arch. Pharm. Res. 2002, 25, 250.

6. Abou-Elenien, G. M.; Ismail, N. A.; El-Maghraby, A. A.; AlAbdallah, G. M.; Electroanal. Chem. 2001, 13, 1022.

7. Gao, J.; Shopes, R. J.; Wright, C. A.; Biochim. Biophys. Acta 1990, 96, 1015.

8. Qu, X.; Lu, T.; Dong, S.; J. Mol. Catal. 1995, 102, 111.

9. Sawyer, D. T.; Sobkowiak, A.; Roberts Jr., J. L.; Electrochemistry for Chemists, John Wiley \& Sons: New York, 1995. 
10. Bard, A. J.; Faulkner, L. R.; Electrochemical Methods, Fundamentals and Applications, John Wiley \& Sons: New York, 1980.

11. Hu, I. F.; Karweik, D. H.; Kuana, T.; J. Electroanal. Chem. 1985, $188,59$.

12. Brautigan, D. L.; Ferguson, M. S.; Margoliash, E.; Methods Enzymol. 1978, 53, 128.

13. Henryk, F.; Anna, C.-J.; Waleria, R.; Henryk, T.; Phosphorus, Sulfur Silicon Relat. Elemen. 2000, 164, 67.

14. Weisshar, D. E.; Walczak, M. M.; Porter, M. D.; Langmuir 1993, 9, 323.

15. Zhong, C.-J.; Porter, M. D.; J. Am. Chem. Soc. 1994, 116, 11616.

16. Lamp, B. D.; Hobara, D.; Porter, M. C.; Niki, K.; Cotton, T. M.; Langmuir 1997, 13, 736.

17. Walczak, M. M.; Alves, C. A.; Lamp, B. D.; Porter, M. D.; J. Electroanal. Chem. 1995, 396, 103.

18. Diógenes, I. C. N.; Sousa, J. R.; Carvalho, I. M. M.; Temperini, M. L. A.; Tanaka, A. A.; Moreira, I. S.; Dalton Trans. 2003, 11, 2231.

19. Baldwin, J.; Schuler, N.; Butler, I. S.; Andrews, M. P.; Langmuir 1996, 12, 6389.

20. Sousa, J. R.; Batista, A. A.; Diógenes, I. C. N.; Andrade, G. F. S.; Temperini, M. L. A.; Lopes, L. G. F.; Moreira, I. S.; J. Electroanal. Chem. 2003, 543, 93.

21. Hong, H.-G.; Park, W.; Electrochim. Acta 2005, 51, 579.

22. Shao, H. B.; Yu, H. Z.; Cheng, G. J.; Zhang, H. L.; Liu, Z. F.; Ber Bunsenges, Phys. Chem. 1998, 102, 111.

23. Karpovich, D. S.; Blanchard, G. J.; Langmuir 1994, 10, 3315.

24. Diógenes, I. C. N.; Nart, F. C.; Temperini, M. L. A.; Moreira, I. S.; Inorg. Chem. 2001, 40, 4884.

25. Diógenes, I. C. N.; Nart, F. C.; Temperini, M. L. A.; Moreira, I. S.; Electroanalysis 2002, 14, 153.

26. Schönenberger, C.; Sondag-Huethorst, J. A. M.; Jorristma, J.; Fokkink, L. G. J.; Langmuir 1994, 10, 611.
27. Duan, L.; Garret, S. J.; J. Phys. Chem. B 2001, 105, 9812.

28. Yang, G. H.; Liu, G. Y.; J. Phys. Chem. B 2003, 107, 8746.

29. Cyganik, P.; Buck, M.; Wilton-Ely, J. D. E. T.; Wöll, C.; J. Phys. Chem. B 2005, 109, 10902.

30. Azzam, W.; Fuxen, C.; Birkner, A.; Rong, H. T.; Buck, M.; Wöll, C.; Langmuir 2003, 19, 4958.

31. Eddowes, M. J.; Hill, H. A. O.; J. Am. Chem. Soc. 1979, 101, 4461.

32. Chen, X.; Ferrigno, R.; Yang, J.; Whitesides, G.; Langmuir 2002, 18, 7009 .

33. Zhou, J.; Zheng, J.; Jiang, S.; J. Phys. Chem. B 2004, 108, 17418.

34. Nicholson, R. S.; Anal. Chem. 1965, 37, 1351.

35. Hawkridge, F. M.; Taniguchi, I.; Comm. Inorg. Chem. 1995, $17,163$.

36. Taniguchi, I.; Toyosawa, K.; Yamaguchi, H.; Yasukouchi, K.; J. Electroanal. Chem. 1982, 140, 187.

37. Saji, T. Y.; Aoyagui, S.; J. Electroanal. Chem. 1975, 61, 147.

38. Endicott, J. F.; Schroeder, R. R.; Chidester, D. H.; Ferrier, D. R.; J. Phys. Chem. 1973, 77, 2579.

39. Amatore, C.; Savéant, J.-M.; Tessier, D.; J. Electroanal. Chem. 1983, 147, 39.

40. Chailapakul, O.; Crooks, R. M.; Langmuir, 1993, 9, 884.

41. Saji, T. Y.; Maruyama, Y.; Aoyagui, S.; J. Electroanal. Chem. 1978, 86, 219.

42. Bryant, M. A.; Crooks, R. M.; Langmuir 1993, 9, 385.

43. Taniguchi, I.; Iseki, M.; Yamaguchi, H.; Yasukouchi, K.; J. Electroanal. Chem. 1985, 186, 299.

44. Zhao, J.; Luo, L.; Yang, X.; Wang, E.; Dong, S.; Electroanalysis 1999, 11, 1108 .
Received: September 28, 2007 Web Release Date: April 18, 2008 